\title{
Optimal central-place foraging by beavers: Tree-size selection in relation to defensive chemicals of quaking aspen
}

\author{
John M. Basey ${ }^{1, *}$, Stephen H. Jenkins ${ }^{1}$, and Peter E. Busher ${ }^{2}$ \\ ${ }^{1}$ Department of Biology, University of Nevada, Reno, NV 89557, USA \\ ${ }^{2}$ College of Basic Studies, Boston University, 871 Commonwealth Avenue, Boston, MA 02215, USA
}

Summary. At a newly occupied pond, beavers preferentially felled aspen smaller than $7.5 \mathrm{~cm}$ in diameter and selected against larger size classes. After one year of cutting, $10 \%$ of the aspen had been cut and $14 \%$ of the living aspen exhibited the juvenile growth form. A phenolic compound which may act as a deterrent to beavers was found in low concentrations in aspen bark, and there was no significant regression of relative concentration of this compound on tree diameter. At a pond which had been intermittently occupied by beavers for over 20 years, beavers selected against aspen smaller than $4.5 \mathrm{~cm}$ in diameter, and selected in favor of aspen larger than $19.5 \mathrm{~cm}$ in diameter. After more than 28 years of cutting at this site, $51 \%$ of the aspen had been cut and $49 \%$ of the living aspen were juvenileform. The phenolic compound was found in significantly higher concentrations in aspen bark than at the newly occupied site, and there was a significant negative regression of relative concentration on tree diameter. The results of this study show that responses to browsing by trees place constraints on the predictive value of standard energy-based optimal foraging models, and limitations on the use of such models. Future models should attempt to account for inducible responses of plants to damage and increases in concentrations of secondary metabolites through time.

Key words: Castor canadensis - Populus tremuloides - Optimal foraging - Central-place foraging - Plant defense Juvenile-form plants

Beavers (Castor canadensis) are central place foragers, moving out from their ponds to select and cut trees, then transporting them back to the ponds to be fed on immediately or stored for later use (Jenkins 1980). In general, beavers tend to favor small trees over large ones of the same species (Aldous 1938; Stegeman 1954; Hall 1960; Jenkins 1979, 1980; Pinkowski 1983; Belovsky 1984a), and show stronger preferences for small trees at greater distances from shore (Jenkins 1980), consistent with a recent model of size/distance relationships (Schoener 1979; Jenkins 1980).

Most models of size/distance relationships are based on the assumption that central place foragers select foods to maximize net rates of energy return (Orians and Pearson

\footnotetext{
* Current address and address for offprint requests: School of Natural Resources, University of Michigan, Ann Arbor, MI 48109-1115, USA
}

1979; Schoener 1979; Jenkins 1980; Lessels and Stephens 1983). There have been a number of tests of such models in recent years (Davidson 1978; Carlsson 1983; Carlsson and Moreno 1985; Krebs and Avery 1985; McGinley and Whitham 1985). However, beavers differ from most other central place foragers in both their type of "prey" (trees), and the fact that they are smaller than their prey. Schoener (1979) suggested that the predicted size/distance relationship of increasing preferences for large prey at greater distances from the central place, applicable to the typical situation of the predator being larger than its prey, should be reversed when the predator is smaller than its prey. Field data on tree-size selection by beavers is consistent with this hypothesis (Jenkins 1980).

A factor which may confound interpretation of tree size selection by beavers in terms of energetic models is the induction of chemical defenses in juvenile-form plants of some species. Heavy browsing causes certain plants to produce suckers which exhibit juvenile characteristics (Bryant and Kuropat 1980; Janzen and Martin 1982; Reichardt et al. 1984; Bryant et al. 1985), manifested by strong apical dominance, absence of lateral branching, and large green leaves (Kramer and Koslowski 1979). In feeding on certain species of the Salicaceae, hares (Lepus spp.) avoid juvenileform suckers when adult-form suckers are present. The avoidance of juvenile-form quaking aspen (Populus tremuloides) and balsam poplar (Populus balsamifera) by snowshoe hares (Lepus americanus) appears to be caused by high concentrations of terpenes and phenolic resins (Bryant 1981), and the avoidance of juvenile-form feltleaf willow (Salix alexensis) is correlated with low nutritional quality (Bryant et al. 1985). Similarly, the juvenile forms of six willow (Salix spp.) species native to Finland are avoided by mountain hares (Lepus timidis), and phenolic glycosides which are more concentrated in the juvenile-forms than the adult-forms of willows are demonstrated deterrents to feeding by mountain hares (Tahvanainen et al. 1985). In the Betulaceae, high levels of deterrent secondary compounds have been isolated and identified in juvenile-form suckers. Papyriferic acid in Alaska paper birch (Betula resinifera) and pinosylvin and pinosylvin methyl ether in green alder (Alnus crispa) are found in higher concentrations in the juvenile-forms than the adult-forms of these species, and are avoided by snowshoe hares (Reichardt et al. 1984; Clausen et al. 1986).

Data gathered by one of us (PB) at Sagehen Creek, a site which had been occupied intermittently by beavers 
for more than 20 years (Busher 1987) showed selection against small quaking aspen ( $P$. tremuloides), contrary to predictions of a model based on maximization of net rate of energy gain (Schoener 1979), and unlike previous field data for aspen (Aldous 1938; Stegeman 1954; Hall 1960; Pinkowski 1983; Belovsky 1984a). To account for the unusual observation of preference for large aspen at this site, we hypothesized that heavy cutting in an area induces chemical defenses in aspen suckers, which in turn causes beavers to shift their preferences from small suckers to larger mature trees.

In this study, we compared selection by beavers for aspen of various sizes at two sites: Sagehen Creek, where trees had been heavily utilized by beavers for more than 20 years before the selection data were collected, and Little Valley, which was newly occupied by beavers at the time of data collection. We predicted that: (1) the relative abundance of juvenile-form suckers should be higher at Sagehen Creek; (2) there should be greater concentrations of a plant secondary compound unpalatable or toxic to herbivores in aspen bark at Sagehen Creek than in aspen bark at Little Valley; (3) there should be a negative correlation between the concentration of this plant secondary compound and tree diameter at Sagehen Creek but not at Little Valley, if the compound persists in aspen which develop from juvenile-form suckers; and (4) beavers at Little Valley should prefer small aspen, in contrast to the preference for large aspen noted at Sagehen Creek. Our general objective is not to show that standard energy-based optimal foraging models are inappropriate for herbivores, but rather to define the limitations of such models, at least for beavers feeding on trees.

\section{Methods}

\section{Study site}

The newly occupied beaver pond was located on Franktown Creek, Little Valley, Washoe County, Nevada, in the Toiyabe National Forest. The pond was located in the center of a Populus tremuloides stand, with Abies concolor, Pinus contorta, Pinus jeffreyil, and Alnus tenuifolia scattered throughout the area. Two beavers were present at the pond, and they had colonized the site in the fall of 1984 . We collected data at Little Valley between June 1985 and February 1986.

The heavily utilized site was located at the University of California research station on Sagehen Creek, Nevada County, California. The area was characterized by $P$. tremuloides, with Salix spp., Alnus tenuifolia, Abies concolor, and Pinus contorta scattered throughout the area. PB collected tree-size selection data at Sagehen Creek in 1978, and the pond had been intermittently occupied for at least 20 years (Busher 1987). There were 4 beavers ( 2 adults and 2 kits) present at this pond in 1978 (Busher 1980). We returned to Sagehen Creek in 1986 to collect bark samples for chemical analysis and to determine the frequency of cut aspen and of juvenile-form suckers at the site. Few trees freshly cut by beavers were present in 1986, so we couldn't make an unbiased estimate of size preferences at this time (if the last beaver cutting had occurred in 1978, then an estimate of preference made in 1986 would include an unknown number of small trees which sprouted after 1978 , and hence were unavailable to beavers in 1978).

\section{Data collection}

We collected data on aspen availability, extent of cutting by beavers, relative abundance of juvenile-form aspen, and size preferences of beavers cutting aspen stems at both Little Valley and Sagehen Creek. We began collecting data on tree cutting at Little Valley in June 1985, by marking each tree previously cut by a beaver. Records on newly cut trees were made once a week thereafter through November 1985 and once every three weeks through February 1986. At Sagehen Creek data on trees cut since approximately the previous fall were collected in June 1978. These trees were distinguished from older cuts by the color and condition of the stump. At both sites, we measured diameters of cut trees at the height of the cut. We used 5 transects at Little Valley in June 1986 and 3 transects at Sagehen Creek in June 1978 to assess size distributions of available trees. At each site, $30 \mathrm{~m}$ by $5 \mathrm{~m}$ transects were randomly placed in the major area of beaver tree-cutting activity, and positioned perpendicular to the shoreline of the pond. Each transect was subdivided into $103 \mathrm{~m}$ by $5 \mathrm{~m}$ plots. In each plot, the species identities of all trees were recorded and their diameters were measured at a height $30 \mathrm{~cm}$ from the ground (the approximate height at which beavers cut trees).

We estimated the relative abundance of juvenile-form aspen in July 1986 and the proportion of trees cut in November 1986, from 5 transects at each site. In each transect we recorded the number of cut and uncut aspen and the ratio of juvenile-form aspen stems to total uncut aspen. Changes at Sagehen Creek may have occurred between 1978 and 1986, and data collected on extent of cutting and percent of juvenile-form aspen in 1986 may not be representative of the Sagehen Creek site of 1978. However, since the pond at Sagehen Creek had been occupied by beavers for such a long time prior to 1978 , we assume that there was less difference in the characteristics of the Sagehen Creek site between 1978 and 1986 than between Sagehen Creek in either 1978 or 1986 and the newly occupied Little Valley site in 1986.

\section{Bark chemistry}

At each site, we collected bark from 50 randomly chosen trees of various diameters during September 1986. The samples were placed into an ice bath immediately and were finally frozen at $-30^{\circ} \mathrm{C}$ until extraction procedures were completed.

Secondary compounds were extracted with $10 \mathrm{ml}$ of $95 \%$ methanol added to $0.25 \mathrm{~g}$ of bark which had been finely cut with scissors. The mixture was then ground up with a mortar and pestle for five minutes. The samples were microfiltered and then analyzed by high performance liquid chromatography (HPLC). The HPLC consisted of an LDC dual pump solvent programmable system. The compounds were separated on a $\left(\mathrm{C}_{18}\right.$, Waters Associates $25 \mathrm{~cm} \times 4.6 \mathrm{~mm}) 10 \mu \mathrm{m}$ reverse phase column. The solvent system consisted of $1 \%$ acetic acid in water and acetonitrile, which was programmed from $10 \%$ to $70 \%$ acetonitrile using a linear gradient over $20 \mathrm{~min}$. The flow rate was set at $1.5 \mathrm{ml} / \mathrm{min}$. Compounds were detected using a variable wavelength LDC absorbance detector set at $280 \mathrm{~nm}$. External standards of the phenolic glycosides salicin, salicortin, tremulacin, and tremuloidin were injected every tenth trial to estimate variation in the HPLC between trials, and on several successive runs the standards were injected in differ- 




Fig. 1. Use of quaking aspen by beavers at Sagehen Creek and Little Valley through 1986. Use is expressed as percentages of available trees in representative transects at each site which had been cut by beavers

ent known concentrations to estimate the relationship of peak heights to concentrations of the compounds. We assumed that peak heights of compounds other than the standards would change in proportion to the peak heights of the standards as concentrations were varied.

\section{Results}

Approximately $23 \%$ of all aspen trees within $3 \mathrm{~m}$ of shore had been felled at Sagehen Creek prior to 1977, when we began collecting data on tree size selection. By contrast, only $3.8 \%$ of aspen within $3 \mathrm{~m}$ of shore had been felled at Little Valley prior to the beginning of data collection at that site in 1985 . The difference in percentage of trees felled is significant $(Z=2.38, P<0.02)$, in support of our assumption that longer occupancy by beavers at Sagehen Creek was reflected in greater aspen utilization than at Litthe Valley. Furthermore, $11 \%$ of aspen within $12 \mathrm{~m}$ of shore and $3.6 \%$ of aspen within $30 \mathrm{~m}$ of shore had been felled by beavers at Sagehen Creek by 1977, compared with $2.3 \%$ $(Z=2.66, P<0.01)$ and $1.1 \%(Z=2.26, P<0.05)$ respectively at Little Valley by 1985 . By 1986 at Sagehen Creek, $51 \%$ of the total available aspen within $30 \mathrm{~m}$ of shore had been cut by beavers (Fig. 1), and $49 \%$ of the living trees exhibited the juvenile growth form (Fig. 2). By contrast after one year of cutting at Little Valley, only $10 \%$ of the total aspen were cut (Fig. 1) and only 14\% of the living trees exhibited the juvenile growth form (Fig. 2). Both the amount of cutting (Fig. 1) and the proportion of juvenile form aspen (Fig. 2) within $30 \mathrm{~m}$ of shore were significantly greater at Sagehen Creek than at Little Valley $(Z=14.37$, $P<0.001, Z=10.67, P<0.001$, respectively). We didn't assess the relative abundance of juvenile-form aspen at Sagehen Creek in 1978 but indirect evidence, discussed below, suggests that juvenile-form aspen may have been common at that time also.

In a companion study using cafeteria-style feeding experiments in the field, we showed that beavers preferred branches from adult trees and adult-form suckers to juvenile-form suckers, and that the juvenile-form suckers had significantly greater concentrations of a phenolic compound which appears to be a feeding deterrent to beavers (Basey

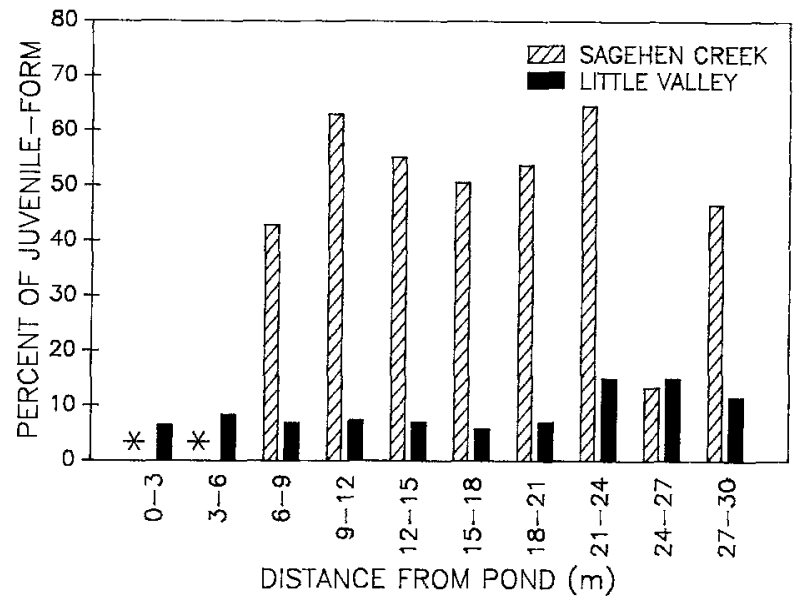

Fig. 2. Percentages of quaking aspen at Sagehen Creek and Little Valley which had the juvenile growth form in 1986. No living trees were present at $0-3$ or $3-6 \mathrm{~m}$ from the pond at Sagehen Creek

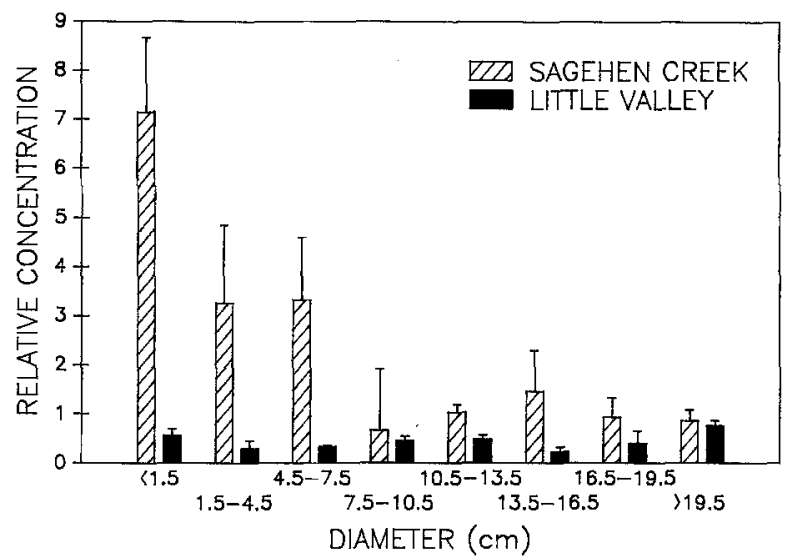

Fig. 3. Relative concentrations (peak heights) of the phenolic compound in quaking aspen bark as a function of tree diameter at Sagehen Creek and Little Valley. Error bars represent one standard error

et al., unpublished work). At Sagehen Creek, there was a significant negative regression of relative concentration of this compound on tree diameter (Fig. $3 ; F=5.60, d . f .=1$, $49, P<0.05)$. At Little Valley, relative concentrations of this compound were much lower than at Sagehen Creek (Fig. $3 ; t=4.59, P<0.001$ ) and there was no significant regression of concentration on tree diameter $(F=3.15, d . f .=$ $1,49,0.10<0.20$ ).

Beavers at both sites showed highly significant selection of trees for cutting based on diameter class (Fig. $4 ; G$-tests of goodness-of-fit of observed numbers of trees felled to expectations based on relative availabilities of the various diameter classes: Little Valley, $G=98.5, d . f .=7, P<0.001$; Sagehen Creek, $G=191.5, d . f .=7, P<0.001$ ). At Sagehen Creek in 1977-1978, there was a significant negative rankorder correlation between electivity and diameter class $\left(r_{s}=\right.$ $-0.976, P<0.01)$. Beavers at Little Valley showed the opposite pattern in $1985-1986\left(r_{s}=+0.881, P<0.05\right)$. At Little Valley, beavers preferred trees less than $7.5 \mathrm{~cm}$ in diameter and selected against larger trees; at Sagehen Creek, beavers selected against trees less than $4.5 \mathrm{~cm}$ in diameter and preferred trees larger than $19.5 \mathrm{~cm}$ in diameter (Fig. 4). 


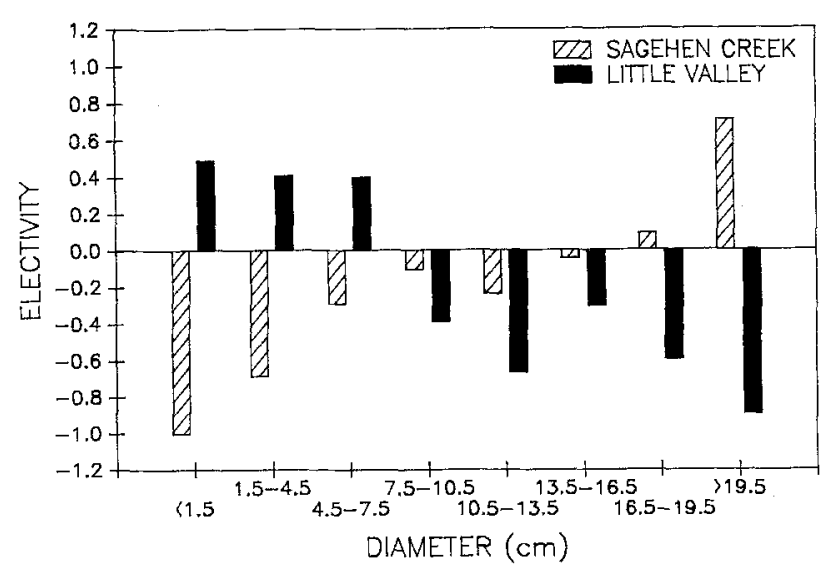

Fig. 4. Electivities of beavers at Sagehen Creek and Little Valley for aspen of various diameter classes. Electivities were calculated according to formulas 3 and 15 of Chesson (1983), where $n_{i \mathrm{o}}$ was an estimate of the total number of trees in size class $i$ available at the beginning of the cutting period (1977-1978 at Sagehen Creek, 1985-1986 at Little Valley), based on $5 \mathrm{~m}$ by $30 \mathrm{~m}$ transects ( 3 at Sagehen Creek, 5 at Little Valley), and $r_{i}$ was the number of trees in size class $i$ felled by beavers during the specified cutting period. The range of possible electivity values is from +1.0 to -1.0 , with values greater than 0 indicating selection in favor of a particular diameter class and values less than 0 indicating selection against a particular diameter class

\section{Discussion}

A common response of trees to browsing is the production of saplings which exhibit juvenile characteristics (Klein 1977; Bryant and Kuropat 1980; Janzen and Martin 1982; Reichardt et al. 1984; Bryant et al. 1985; Tahvanainen et al. 1985; Clausen et al. 1986). This study shows that a similar response to browsing occurs in quaking aspen at Sagehen Creek. In 1986 the Sagehen Creek site had been intermittently occupied for over 28 years, and the relative abundance of juvenile-form suckers was over 6 times that found at Little Valley which had only been occupied for 2 years. We assume that a similar condition was present at Sagehen Creek in 1978 after 20 years of occupancy by beavers, and that the area had an abundance of juvenile-form suckers when the selection data were collected. This assumption is supported by the fact that trees as large as $4.5-7.5 \mathrm{~cm}$ in diameter at Sagehen Creek had elevated concentrations of the phenolic compound (Fig. 3) which we hypothesize is a feeding deterrent for beavers (Basey et al., unpublished work). We determined the ages of 10 trees at Sagehen Creek with diameters between 2.7 and $6.6 \mathrm{~cm}$; all but one of these (the smallest) was greater than 9 years old. Furthermore, juvenile-form suckers usually have high concentrations of the phenolic compound, whereas adult-form suckers usually have low concentrations (Basey et al., unpublished work). This suggests that many trees with high concentrations of the phenolic compound in 1986, when we did the biochemical analyses, were present as juvenile-form sprouts or suckers in 1977-1978, when the size selection data were collected at Sagehen Creek. It seems likely that such sprouts and suckers had high concentrations of the compound at that time also.

Figure 4 shows a major difference in size selection of aspen by beaver colonies: beavers at Little Valley preferentially cut aspen less than $7.5 \mathrm{~cm}$ in diameter, but at Sagehen
Creek, beavers selected against aspen less than $4.5 \mathrm{~cm}$ in diameter. The electivity indices indicate that opposite selection patterns were characteristic of beavers at the two sites.

Results of a previous study of tree-size selection at Sagehen Creek were consistent with results from this study. Hall (1960) examined size selection of quaking aspen by beavers in five colonies at Sagehen Creek. He collected data in 1952 and 1953. Seven years prior to Hall's study, beavers were introduced to Sagehen Creek for the first time by the California Department of Fish and Game, which released four animals. Therefore, several of the colonies which Hall studied probably had been occupied for only a few years. His results showed that beavers preferred aspen from 2.5 to $7.5 \mathrm{~cm}$ in diameter. Aspen smaller than $2.5 \mathrm{~cm}$ were not preferred by the beavers, which is consistent with our hypothesis if indeed the beavers had occupied the study site for only a few years and the juvenile-form suckers had not grown over $2.5 \mathrm{~cm}$ in diameter.

Food selection by beavers may be explained by two general hypotheses. The first states that herbivores forage to satisfy nutritional requirements with minimum ingestion of toxic secondary compounds (Freeland and Janzen 1974; Sinclair et al. 1982; Sinclair and Smith 1984; Palo 1984), and the second states that herbivores should select food to maximize their net rates of energy intake (Pyke et al. 1977; Belovsky 1984 b). The two hypotheses are not mutually exclusive. When a certain food has poor nutritional content, or poor palatability due to secondary metabolites, maximizing net rate of energy intake may be an advantageous strategy of food selection; but when nutritional and chemical constraints are not present, selecting food to maximize net rate of energy intake should be a beneficial strategy (Belovsky 1981). At any given time an herbivore may use either of the two strategies depending on the condition of its food supply.

Certain tests of optimal foraging models which have predicted selection of tree sizes by beavers based on net rate of energy return have been successful (Jenkins 1980; Pinkowski 1983; Belovsky 1984a). Jenkins (1980) showed that, for most tree genera in central Massachusetts, beavers cut a smaller range of sizes far from shore than close to shore, and relatively more small trees and fewer large trees at greater distances. These results were consistent with an optimal foraging model proposed by Schoener (1979). Belovsky (1984a) demonstrated that beaver foraging on Isle Royale National Park in Michigan was consistent with a linear programming model of herbivore optimal foraging. Neither model included consideration of nutritional value, or toxic and unpalatable secondary metabolites that may be present in trees of various sizes.

The results of this study show that beavers selected aspen trees by size in two different manners which support both of the hypotheses mentioned previously: (1) when juvenile-form aspen were uncommon, presumably due to low levels of prior beaver activity, the beavers chose aspen by size following predictions of optimal foraging models and (2) when beaver activity was higher for longer periods of time, apparently resulting in greater abundance of juvenileform aspen, the beavers selected large trees which likely had low concentrations of a specific phenolic compound, which is avoided by beavers in feeding experiments (Basey et al., unpublished work). Thus, responses to browsing by trees place constraints on the predictive value of standard energy-based optimal foraging models, and limitations on 
the use of such models. Future models should attempt to account for inducible responses of plants to damage and increases in concentrations of certain secondary metabolites through time.

Acknowledgements. We thank G. Miller and R. Lindroth for advice on the biochemical analysis and J. Bryant, R. Lindroth, and D. Prusso for comments on the manuscript.

\section{References}

Aldous SE (1938) Beaver food utilization studies. J Wildl Mgmt $2: 215-222$

Belovsky GE (1981) Food plant selection by a generalist herbivore: the moose. Ecology 62:1020-1030

Belovsky GE (1984a) Summer diet optimization by beaver. Am Mid Nat $111: 209-222$

Belovsky GE (1984b) Herbivore foraging: a comparative test of three models. Am Nat 124:97-115

Bryant JP (1981) Phytochemical deterrence of snowshoe hare browsing by adventitious shoots of four Alaskan trees. Science 213:889-890

Bryant JP, Kuropat PJ (1980) Selection of winter forage by subarctic browsing vertebrates: the role of plant chemistry. Ann Rev Ecol Syst 11:261-285

Bryant JP, Wieland GD, Clausen T, Kuropat P (1985) Interactions of snowshoe hare and felteaf willow in Alaska. Ecology $60: 1564-1573$

Busher PE (1980) The population dynamics and behavior of beavers in the Sierra Nevada. PhD diss, University of Nevada, Reno, Reno Nevada, xii +147 pp

Busher PE (1987) Population parameters and family composition of beaver in California. J Mamm 68:860-864

Carlsson A (1983) Maximizing energy delivery to dependent young: a field experiment with red-backed shrikes (Lanius cullurio). J Anim Ecol 52:697-704

Carlsson A, Moreno J (1985) Central place foraging in wheatears (Oenanthe oenanthe L): foraging itineraries when feeding nestlings. Behav Ecol Sociobiol 16:307-316

Chesson J (1983) The estimation and analysis of preference and its relationship to foraging models. Ecology 64:1297-1304

Clausen TP, Reichardt PB, Bryant JP (1986) Pinosylvin and pinosylvin methyl ether as feeding deterrents in green alder. J Chem Ecol 12:2117-2131

Davidson DW (1978) Experimental tests of optimal diet in two social insects. Behav Ecol Sociobiol 4:35-41

Freeland WJ, Janzen DH (1974) Strategies in herbivory by mammals: the role of plant secondary compounds. Am Nat 108:269-289

Hall JG (1960) Willow and aspen in the ecology of beaver on Sagehen Creek, California. Ecology $41: 484494$
Janzen DH, Martin PS (1982) Neotropical anachronisms: the fruits the Gomphotheres ate. Science 215:19-27

Jenkins SH (1979) Seasonal and year-to-year differences in food selection by beavers. Oecologia (Berl) 44:112-116

Jenkins SH (1980) A size-distance relation in food selection by beavers. Ecology $61: 740-746$

Klein DR (1977) Winter food preference of snowshoe hares (Lepus americanus) in interior Alaska. Proc Int Congr Game Biol $13: 266-275$

Kramer PJ, Koslowski TT (1979) Physiology of woody plants. Academic Press, New York, New York

Krebs JR, Avery ML (1985) Central place foraging in the European bee-eater, Merops apiaster. J Anim Ecol 54:459-472

Lessels CM, Stephens DW (1983) Central place foraging: single prey loaders again. Anim Behav 31:238-243

Orians GH, Pearsons NE (1979) On the theory of central place foraging. In: Horn DH, Mitchell R, Stairs G (eds) Analysis of ecological systems. Ohio State Univ Press, Columbus, pp 155-177

McGinley MA, Whitman TG (1985) Central place foraging by beavers (Castor canadensis): a test of foraging predictions and the impact of selective feeding on the growth form of cottonwoods (Populus fremontii). Oecologia (Berl) 66:558-562

Palo TP (1984) Distribution of birch (Betula spp.), willow (Salix spp.), and poplar (Populus spp.) secondary metabolites and their potential role as chemical defense against herbivores. J Chem Ecol 10:499-520

Pinkowski B (1983) Foraging behavior of beavers (Castor canadensis) in North Dakota. J Mamm 64:312-314

Pyke GH, Pulliam HR, Charnov EL (1977) Optimal foraging: a selective review of theory and tests. Quart Rev Biol 52:137-154

Reichardt PB, Bryant JP, Clausen TP, Wieland GD (1984) Defense of winter-dormant Alaska paper birch against snowshoe hares. Oecologia (Berl) 65:58-69

Schoener TW (1979) Generality of the size-distance relation in models of optimal feeding. Am Nat 114:902-914

Sinclair ARE, Krebs CJ, Smith JNM (1982) Diet quality and food limitation in herbivores: the case of snowshoe hare. Canad $\mathbf{J}$ Zool 60:889-897

Sinclair ARE, Smith JNM (1984) Do plant secondary compounds determine feeding preferences of snowshoe hares? Oecologia (Berl) 61:403-410

Stegeman LC (1954) The production of aspen and its utilization by beaver on the Huntington Forest. J Wildl Mgmt 18:348-358

Tahvanainen J, Helle E, Julkunen-Titto R, Lavola A (1985) Phenolic compounds of willow bark as deterrents against feeding by mountain hare. Oecologia (Berl) 65:319-323

Received September 3, 1987 